\title{
IT Procurement Case Study of the Japanese Government within the Institutional Theory Context

\author{
KANASAKI Kentaro
}

\begin{abstract}
Japanese government has sought to create and implement an IT $^{1}$ procurement system that fosters competitive bidding. This study examines 31 IT procurement case studies surrounding the 2016 launch of Japan's social security and tax number system ${ }^{2}$ with which the author was directly involved. It identifies a disjunction between IT procurement as a legal and a social system, wherein the government and vendors acknowledge that some vendors will inevitably be awarded contracts. The Japanese government should thus reconsider its IT procurement system and abandon competitiveness as a goal.
\end{abstract}

\section{Keywords}

IT procurement; Government; My Number; Institutional theory; Shared belief

\section{Introduction}

Usage of IT in the administration of governmental entities has progressed in Japan, and IT costs reduction has become an important issue. Government Electronic Procurement System is a system common to ministries that electronically conducts procurement procedures for goods and services facilitated by the government and some public works via the Internet. Some ministries and agencies that operated individual electronic procurement systems are supposed to be integrated into this system.

The Japanese government formulated a basic policy on government IT procurement [Resolution of the Council of Government Agency CIOs, 2007] in 2007 for realizing competitive environment and securing transparency and fairness in the governmental procedures, and IT procurement by ministries and agencies is now conducted based on it. Moreover, ministries and agencies upgraded IT systems en masse to prepare for the 2016 launch of Japan's social security and tax number system (SSTN system). This study elucidates the real status of the Japanese government's IT procurement based on this procurement case and its features through a theoretical observation to contribute to future improvements.

In this study, Section 2 illustrates a literature review on the background of government procurement. Section 3 presents the method and data of the investigation. Section 4 states the results. Section 5 presents the considerations. Finally, Section 6 concludes the study.

\footnotetext{
${ }^{1}$ IT means software and hardware that utilize information and communication technology.

${ }^{2}$ In Japan, the social security tax number system started in 2016.
} 


\section{Literature Review}

Previous research in auction theory [McAfee \& McMillan, 1987; Milgrom, 1989; Milgrom \& Weber, 1982] has perceived government procurement as a noncooperative game with no prebinding agreements between ministries, agencies, and vendors and as a game with incomplete information [Harsanyi, 1967] with an informational asymmetry between orderers and vendors. Kanemoto [1991] argues that the essence of a procurement system is that the procuring parties can design the procurement system by supplementing their insufficient information through competition based on the system. According to this thought, implementation of a competitive bidding system that secures competitiveness makes the procurement intended by the procuring parties possible. However, while the IT procurement by the government is conducted under the basic policy that aims at securing competitiveness, lack of competitiveness is pinpointed in the Board of Audit of Japan's report [2011]. In previous studies [Masanori, 2012; Tomohiro, 2013; Yukio, 2008], the lack of capacity on the procurement side was pinpointed as a factor. The procurement capacity may be achieved through well coordination, efficiency in deliver, and reducing information asymmetry [Phillips et al., 2008]. This raises a question that previous research may not apply to IT procurement. If the ability of the procurement side is the essence of the problem, the basic guidelines should ensure competitiveness. The auction theory is premised on the information asymmetry and does not assume that the procurement side is required to have the ability to eliminate information asymmetry. This study proposes that there may be a problem with the procurement legal system and its operation.

However, the actual state of IT procurement by the government such as the status of procurement by ministries and agencies or the results of their procurement rarely provide a clear view. Improvements in procurement systems and their operations necessitate addressing the issues based on concrete case studies, but this has not progressed.

Further, we will clarify the characteristics of Japanese government's IT procurement by theoretically reviewing it within the context of previous research. In this research, we will use previous research in institutional theory from the viewpoint of what role procurement plays in the information system field. Institutional theory studies that analyze social systems have been focused on the nature and role of institutions [Scott, 1995; Kohno \& Itabashi, 1998]. They are also studying the concept of a system, what is a system [Aoki, 2001; North, 1990; North, 1991]. In this study, we will use the previous research to consider the actual situation of information system procurement in Japan in line with institutional theory research. This study is novel even in light of recent theoretical research on public procurement in recent years [Flynn \& Davis, 2014; Martti et al., 2017; Saarela et al., 2018; Shkolnik et al., 2018], as there is no previous research theoretically discussing the actual situation of information system procurement by the Japanese government and local governments.

We can thus conclude the aims of this study answer the following questions:

1. What is the role that procurement plays in the information system field?

2. What is the actual situation of information system procurement in Japan in line with institutional theory research? 


\section{Data and Methods}

To generalize the actual status of IT procurement by the government from the procurement examples, it is necessary to analyze more than one case with the same procumbent subject, object, and environment. As the procurements by ministries and agencies are conducted individually, obtaining cases of such examples are extremely difficult, and no previous studies exist on them. The difficulty may be because some institutions do not publish the information of the procurements. Moreover, the issue comes from the absence of an integrated source for the procurements data.

This study will proceed with case studies. Given the difficulty of obtaining quantitative data for all information system procurement cases in government and local governments, we conduct case studies on one or more cases where accurate information can be obtained. It is reasonable to attempt generalization based on this. "Multiple case analysis" for analyzing procurement results and "specific case analysis" for analyzing procurement processes are performed to clarify the actual situation and issues.

\section{A. Specific Case}

Procurement of information collaboration system associated with the Social Security and Tax Number is the core of the network for each administrative organization to exchange information using My Number as a key.

\section{B. Multiple Case Analyses}

In this study, the system was classified as a "My Number" system according to the procurement project name and procurement specifications.

The purpose of the renovation is to construct a network for exchanging information with other government agencies using the my number as a key, refurbishing for associating my number with the personal information of the people held in the business system of each ministry.

We analyzed the procurement results of 31 My Number related systems in comparison with the system procurement results of each ministry and agency reported in the 2011 report of the Auditing Institute. The comparative analysis items are as include procurement environment (procurement capability, procurement system, etc.), ratio of general competitive bidding, oneperson bid ratio, average successful bid rate, noncompetitive bid ratio, and percentage of orders received by specific companies.

In the specific case analysis, we used data published by the Cabinet Secretariat and data stored and recorded by the author. The example of procurement as it relates to the introduction of SSTN system presented a rare opportunity in which various ministries and agencies procured the same kind of systems simultaneously. Further, as they include an example in which this author was directly involved, verification is possible on the process and operation by way of participant observation method.

The 31 IT procurement cases of the ministries and agencies were analyzed to introduce the SSTN system based on the public data published on the websites of the ministries, agencies, and official gazettes [Kentaro et al., 2018]. The information that has been published in the official gazette includes the procurement items, such as procurement capability, procurement system; the bidding information; successful bid; and the orders received by specific companies. 
For information on procurement items of each ministry and agency, we used information published in the official gazette by the information retrieval service and information published by each institution on the homepage. Other information included the Cabinet Office e-bidding and ticket gate system (discontinued on July 31, 2014). Information from the e-bidding system of each ministry and agency before the transition to government electronic procurement (GEPS) [Note] was used. With the exception of some information published in the official gazette, all of them were just before the start of comprehensive operational testing.

Further, we verified the actual status of procurement process and system operation of the procurement example of systems related to SSTN system by the Cabinet Secretariat based on public data and the information that was used by Kentaro [2019]. Based on these, we will then review the actual status along previous research in auction and institutional theories.

\section{Results}

\section{A. Results of Procurement by Ministries and Agencies}

It was found that $80.6 \%$ of SSTN-related IT procurement projects were executed under open competitive bidding. However, of those, $48 \%$ had only one bidder (excluding $85.7 \%$ projects where some bidders other than the successful bidder were unknown), and the ratio of noncompetitive bidding, or negotiating contracts and single-bidder contracts, was as high as $90.0 \%$, if we consider only the projects with known bidders.

It was also found that $96.8 \%$ of contracts (99.1\% in monetary terms) were awarded to any of the five domestic vendors: NTT Communications, NTT Data, NEC, Hitachi, and Fujitsu. Moreover, consortiums among these five large companies made bids and won $12.9 \%$ of contracts awarded. The average successful bid ratio was $89 \%$, even higher for the successful average bid ratio where only one bidder was involved with $95.2 \%$. Hence, this result revealed that sufficient competitiveness was not maintained for the IT procurements by ministries and agencies.

However, no record exists for any SSTN-related IT contract that was not awarded and failed, meaning that all necessary procedures were executed as planned.

\section{B. Actual Status of Procurement Process}

The Cabinet Secretariat developed the core system of the new high security network, established with the "My Number" system, in which the author was directly involved. As the author verified the procurement process and procurement results by participant observation method, while the procurement process was carefully conducted by giving utmost priority to the realization of competitive environment in accordance with the basic policy, it ended up with a sole bidder situation by a consortium of the five large companies failing to realize the competitive environment. Moreover, some challenges such as issues of single-year budgeting and inadequate procurement periods, poor dialog with the vendors, and myopic procurement management were found.

\section{Considerations}

\section{A. Perspective of Our Consideration}

Previous research based on auction theory hold that in the governmental procurement, the lack of information on the part of the orderer can be overcome by utilizing competition among the vendors 
based on the procurement system [Kanemoto, 1991]. Yet, in reality, although the procurement rules that incorporate mechanisms to assure competitiveness are faithfully followed, competition in fact is not secured. This raises the following question: Does the procurement function in action theory still work when it comes to IT procurement? To answer this question, we will examine the actual practice by applying the concept of institutional theory with a viewpoint of what kind of a role procurement as a social system should play. Notably, the term "institution" as used in the institutional theory means, unlike in the procurement system/institution within a legal framework, the role as a social system that procurement itself plays.

\section{B. Characteristics of Procurement as a System}

Scott [1995] categorized systems from a sociological perspective and revealed that three pillars exist in institutions-regulative, normative, and cognitive pillars-and that the emphasized elements differ depending on the institution. Applying this categorization to procurement suggests that the IT procurement that imposes a process intended for securing competitiveness onto both the procuring party and the vendor is a system that emphasizes the regulative pillar. If IT procurement is a regulative system, securing fair process and competitiveness that it aims to achieve should be realized by those involved with enforceability.

However, focusing on the actual practice of IT procurement by the government, the way the procurement process based on basic policy is conducted faithfully by both the procurer and the vendor can be interpreted as a regulative pillar incorporated in the IT procurement. Yet, the actual status where procurement results indicate that competitiveness is not firmly secured can be interpreted that the degree of its regulative pillar has decreased. In other words, we can understand that IT procurement is one in which the degree of regulative pillar that procurement intrinsically possesses has weakened, and while procedural enforceability is in place, enforceability for the realization of competitiveness is nonfunctional.

\section{Are Those the "Rules of the Game"?}

North [1991] conceptualized institutions from the perspective of game theory, arguing that institutions are "the rules of the game" that constrain the players, where the game players in procurement are the ministries and agencies, procuring parties, or individual vendors. If you apply North's concepts, you can interpret procurement as common rules whereby ministries and agencies, or procuring parties and vendors, with the respective strategies of their own, act to obtain their respective benefits (obtaining procured material at economic prices for the government and obtaining profits based on agreements for the vendors) without having a binding agreement among them.

When this concept of North is applied to the actual practice of IT procurement by the government, although the ministries and agencies abide by the procedural rules in the game called IT procurement, it means that rules that should secure the competitiveness are not observed. This is because the government makes non-binding agreements with the vendors. Yet, there is one more important aspect that should not be overlooked, a fact that, in the IT procurement by the ministries and agencies in respect of SSTN, there has never been a case in which the engaging vendor was eventually left determined and the introduction of the system itself became impossible.

According to North's concepts, this means that in the game of IT procurement, there are rules that are abided by (procurement procedures) and rules that are not (securing competitiveness), but as 
far as the results of the game show, the counterparty, which is the final objective of procurement, has been determined. This would mean that the decision on the counterparty of the contract itself is the rule between the procuring parties and the vendors from the beginning but would also mean that the rules of procurement procedure and securing competitiveness are meaningless. In other words, North's concept that regards institution as the "rules of the game" cannot fully explain the roles procurement plays in the field of IT.

\section{D. "Institutions as Shared Beliefs" and Governmental IT Procurement}

Unlike North, who sees institutions as rules of the game, Aoki [2001] defines institution as selfbinding expectations that are shared by the players, and proposes that players' behaviors are conditioned by a compulsion to achieve an equilibrium, and their jointly-held sense of equilibrium comprises "institutions as shared beliefs." In that regard, players neither cooperate nor agree; they implicitly understand the equilibrium (summary expressions) peculiar to the game and are influenced by shared symbols that lead to it. Aoki called groups of individual economic entities "domains" and argued that domains select symbols that simultaneously calibrate the expectations of individual economic entities. Per this idea of Aoki, current government IT procurement involves two domains: government (the procuring party) and the market (vendors) (Figure 1). It can be interpreted that their guiding symbol is the national consensus to bring effective IT to government, and the summary expression is "a situation where an order is eventually placed with one vendor and the IT system is realized."

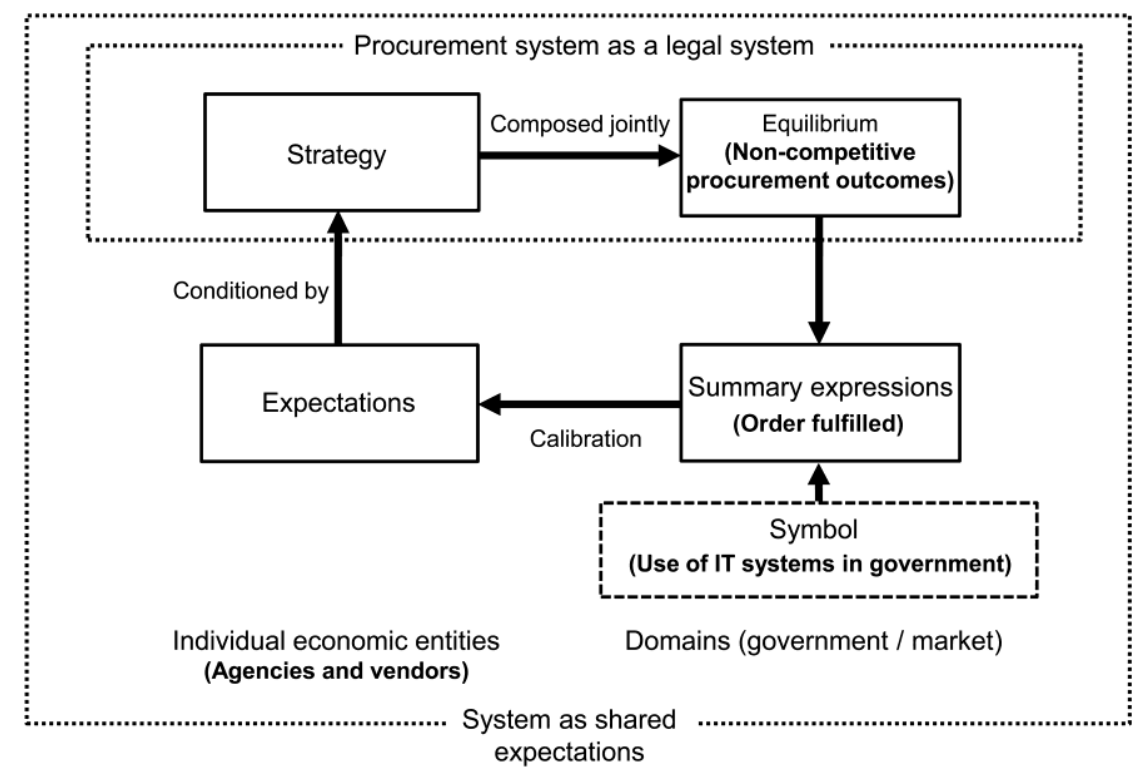

Figure 1 - IT Procurement as an Institution for Sharing (Source: [Aoki, 2001])

Figure 1 demonstrates that the actual situation of IT procurement is not the competitiveness that the procurement system as a legal system aims at, but the establishment of the order itself is shared between the procurement side and the business operator; it shows that the legal system and the institutional system recognized by the procurement side and the operator are different.

Against the background of the fact that the government and the market make the "realization of information system (fulfilling an order)" as their summary expression, each ministry and agency 
and each vendor chooses strategy that implicitly makes this assumption. That is, government imposes procedures intended to assure fairness and transparency to meet their accountability, whereas the only bidding vendors are those who can satisfy the contract and bear its risks. If no single vendor can do so, the risk is diversified by forming a consortium permitted by the system. Furthermore, it can be understood that this results in noncompetitive single-bidding or at-will awards.

\section{Conclusions}

Japan currently has an unobjectionable national consensus to implement effective IT in government administration. In it, IT procurement is motivated, not by a legal system to secure fair procedures and competitiveness, but by the state in which the realization of the systems (fulfilling the order) is shared and recognized by the government and all the vendors comprising the market.

This indicates that a deviation prevails between procurement as a legal system and the system as a social system as perceived by the ministries and agencies who are the procuring entities and the vendors. There is a likelihood that this has caused social diseconomies, impaired understanding, and lack of opacity. Ideally, procurement as a legal system would align with the social system that society perceives it so it can be better trusted and understood by people.

The Japanese government's current procurement system based on competitive bidding seeks to support market mechanisms, but if participants' strategies and behaviors are influenced by "systems as shared beliefs," government needs to rethink IT procurement and aim at procuring necessary information systems at economic prices without regard to competitiveness. For the procurement of large-scale and complex information systems, it is desirable to introduce a dialogbased procurement system, which is used in other countries such as the United Kingdom and the United States, instead of competitive bidding.

\section{References}

[Aoki, 2001] Aoki, M. (2001). Toward a comparative institutional analysis. Tokyo: NTT Publishing.

[Board of Audit of Japan, 2011] Board of Audit of Japan. (2011). Report based on Article 30-2 of the Board of Audit Act, Competitiveness in Contracts of Information Systems, Calculation of Predetermined Prices, and Status of Information Sharing in the Procurement by Ministries and Agencies. doi:http://report.jbaudit.go.jp/org/h23/ZUIJI2/2011-h23-2300-0.htm

[Flynn \& Davis, 2014] Flynn, A., \& Davis, P. (2014). Theory in public procurement research. [Flynn \& Davis, 2014] Journal of Public Procurement, 14, 139-180. doi:https://doi.org/10.1108/JOPP-14-02-2014-B001

[Harsanyi, 1967] Harsanyi, J. C. (1967). Games with incomplete information played by "Bayesian" players, Part I-III. Management Science, 14, 486-502.

[Kanemoto, 1991] Kanemoto, Y. (1991). Economics of government procurement. In Y. Kanemoto \& H. Miyajima (Eds.), Public sector rationalization (pp. 89-110). Tokyo: University of Tokyo Press.

[Kentaro et al., 2018] Kentaro, K., Hiroichi, K., \& Tomokazu, A. (2018). Study of government IT system procurement as seen in case studies of introduction of social security and tax number 
system (My Number Donyu Jirei ni Miru Seifu Jouhou System Choutatsu no Genjou ni Kansuru Kenkyuu). Journal of Information Systems Society of Japan, 14, 13-25.

[Kentaro, 2019] Kentaro, K. (2019). Case studies in IT procurement for government information systems: Procurement of systems for social security and tax number and network systems for provision of information. Journal of Law and Politics, 70, 1-28.

[Kohno \& Itabashi, 1998] Kohno, S., \& Itabashi, Y. (1998). Institutions and Organizations. (W. Scott, Trans.). Tokyo: Accounting and Taxation Institute.

[Martti et al., 2017] Martti, S., Eija-Ritta, N., Matti, M., Ville, I., \& Pekka, L. (2017). Small- and medium-sized enterprises in public procurement in primary social and healthcare services. International Journal of Procurement Management, $11, \quad 76$. doi:https://doi.org/10.1504/IJPM.2018.10009213

[Masanori, 2012] Masanori, S. (2012). Issues in government IT procurement. Legislation and Investigation, 333, 140-159.

[McAfee \& McMillan, 1987] McAfee, R. P., \& McMillan, J. (1987). Auctions and bidding. Journal of Economic Literature, 25, 699-738. doi:http://www.jstor.org/fcgibin/jstor/listjournal.fcg/00220515/.21-.30

[Milgrom \& Weber, 1982] Milgrom, P. R., \& Weber, R. J. (1982). A theory of auctions and competitive bidding. The Econometric Society, 50, 1089-1122. doi:https://doi.org/10.2307/1911865

[Milgrom, 1989] Milgrom, P. R. (1989). Auctions and bidding: A primer. Journal of Economic Perspectives, 3, 3-22. doi:https://doi.org/10.1257/jep.3.3.3

[North, 1990] North, D. (1990). Institutions, institutional change and economic performance. Cambridge, UK: Cambridge University Press.

[North, 1991] North, D. C. (1991). Institutions. The Journal of Economic Perspectives, 5, 97-112. doi:https://www.jstor.org/stable/1942704

[Resolution of the Council of Government Agency CIOs, 2007] Resolution of the Council of Government Agency CIOs. (2007). Basic Policy for Government Procumbent of Information Systems. Retrieved from http://www.soumu.go.jp/main_content/000070266.pdf\#search=\%27

[Saarela et al., 2018] Saarela, M., Niinikoski, E. -R., Muhos, M., \& Isoherranen, V. (2018). Smalland medium-sized enterprises in public procurement in primary social and healthcare services. International Journal of Procurement Management, 11, 76-95. doi:https://doi.org/10.1504/IJPM.2018.10009213

[Scott, 1995] Scott, R. S. (1995). Institutions and organizations. Thousand Oaks, CA: Sage Publications.

[Shkolnik et al., 2018] Shkolnik, I., Bukhtiarova, A., \& Horobets, L., 2018. The efficiency of electronic public procurement system in Ukraine. Public and Municipal Finance, 7, 43-55. doi:https://doi.org/10.21511/pmf.07(3).2018.05

[Tomohiro, 2013] Tomohiro, O. (2013). Problems in Procurement of Information Systems by the Ministry of Government as Seen from the Inspection Results of the Accounting Inspection Office. 
Summary of the Management Information Society Conference 2012 (p. 233). Tokyo: Japan Society for Information and Management

[Yukio, 2008] Yukio, M. (2008). Government procurement issues related to information systems from the viewpoint of information system architecture. The International CIO Journal, 2, 1-11. 